\title{
CARACTERIZAÇÃo MORFOLÓGICA DE CULTIVARES DE ARROZ VISANDO A CERTIFICAÇÃO DA PUREZA VARIETAL*
}

\author{
Morphological characteristics of rice cultivars; application for variety purity certification
}

\author{
Sandro Bonow ${ }^{1}$, Édila Vilela Resende Von Pinho², Antônio Alves Soares², Sancho Siécola Júnior ${ }^{3}$
}

\begin{abstract}
RESUMO
Com o presente trabalho, objetivou-se avaliar a eficiência dos descritores morfológicos, na caracterização de cultivares comerciais de arroz (Oryza sativa L.), servindo como suporte às empresas produtoras de sementes na identificação de cultivares, assim como às exigências da Lei de Proteção de Cultivares. Foram caracterizadas as cultivares de arroz Carisma, IAC 202, Confiança, Douradão, Guarani, Primavera, Canastra e Caiapó. O estudo consistiu de dois experimentos, o primeiro conduzido em casa-devegetação, quando os genótipos foram caracterizados utilizando-se dos descritores morfológicos recomendados para o registro e proteção de cultivares. O segundo experimento foi conduzido em uma área de produção de sementes e consistiu na identificação, por parte de avaliadores, de variedades de arroz contaminantes propositalmente distribuídas junto às cultivares em estudo. Concluiu-se que os descritores morfológicos são úteis, porém, não suficientes para a caracterização e diferenciação de cultivares de arroz. As características morfológicas observadas em sementes e plantas após a antese são as mais adequadas para a caracterização e diferenciação de cultivares. Os genótipos de arroz de sequeiro apresentam grande similaridade morfológica.
\end{abstract}

Termos para indexação: Arroz, marcadores morfológicos, distinção varietal, Oryza sativa L.

\begin{abstract}
This study had the objective of evaluating the efficiency of morphological markers as descriptors for commercial rice cultivars (Oryza sativa L.) to be used in cultivar identification by seed companies, as well as, to fulfill the requirements for cultivar protection law. The studied cultivars were: Confiança, IAC 202, Carisma, Primavera, Guarani, Douradão, Canastra, and Caiapó. This study consisted of two experiments: one, conducted in greenhouse, where the varieties were characterized based on morphological descriptors recommended by protection cultivar law; the other, done in a seed production field that consisted in identification of rice contaminant varieties distributed among the studied cultivars. The morphological descriptors were useful, but not enough to characterize and distict upland rice cultivars; seeds and plants morphological characteristics after anthesis were the most suitable for the characterization and discrimination of varieties; and also, the upland rice genotypes had high morphological similarities.
\end{abstract}

Index terms: Rice, morphological markers, varietal distinction, Oryza sativa L.

(Recebido em 22 de setembro de 2004 e aprovado em 16 de fevereiro de 2006)

\section{INTRODUÇÃO}

O arroz (Oryza sativa L.) é um dos cereais mais cultivados no mundo, juntamente com o milho e o trigo representa mais de $50 \%$ da produção agrícola (GOFF et al., 2002). Na América Latina, o Brasil é o maior produtor, sendo responsável por aproximadamente $88 \%$ da produção de arroz do Mercosul (RIGGATO \& KOHLZ, 1998). A elevada produção de arroz no Brasil e no mundo deve-se à alta tecnologia empregada pelos agricultores, associado ao alto potencial genético das cultivares utilizadas, o qual foi alcançado nos programas de melhoramento genético de arroz (GUIDOLIN, 1993).

Para que todo esforço realizado pelos melhoristas em incorporar as novas características diferenciais às cultivares possa ser desfrutado pelos agricultores, é necessário que as sementes, que são a ligação entre os melhoristas e os agricultores, sejam repassadas com alta qualidade aos produtores. Nesse sentido, as empresas produtoras de sementes procuram monitorar todas as etapas do processo produtivo visando um produto com alta pureza genética, física, fisiológica e sanitária.

A seleção de sementes com alta pureza varietal é o primeiro passo em direção à obtenção da semente de alta qualidade (PESKE \& BARROS, 1996), sendo para isso necessária a correta identificação das cultivares por meio de suas características particulares. No Brasil, a identificação de cultivares é realizada, na maioria das vezes, pelo uso de descritores morfológicos.

\footnotetext{
Engenheiro Agrônomo, Dsc., Pesquisador da Empresa Brasileira de Pesquisa Agropecuária - Embrapa Trigo/Centro Nacional de Pesquisa de Trigo Rodovia BR 285 - Km 294 - Cx. P. 451 - 99.001-970 - Passo Fundo, RS - bonow@cnpt.embrapa.br

Engenheiro Agrônomo, DSc., Professor do Departamento de Agricultura/DAG - Universidade Federal de Lavras/UFLA - Cx. P. 3037 - $37200-000$ Lavras, MG - edila@ufla.br; aasoares@ufla.br

${ }^{3}$ Aluno do curso de Agronomia da Universidade Federal de Lavras/UFLA - Cx. P. 3037 - 37200-000 - Lavras, MG - Bolsista de Iniciação Científica do CNPq .

*Trabalho extraído da tese de Doutorado do primeiro autor, realizado na Universidade Federal de Lavras/UFLA - Lavras, MG.
} 
Além do aspecto relacionado ao controle de qualidade de sementes, outro motivo que tem aumentado significativamente o interesse pela caracterização de cultivares nas últimas décadas é a crescente necessidade de proteção de cultivares comerciais em mercados econômicos cada vez mais competitivos. No Brasil, a Lei de Proteção de Cultivares n. ${ }^{\circ}$. 9.456, sancionada em 25 de abril de 1997, abriu uma nova perspectiva e interesse na proteção e lançamento de materiais genéticos (MILACH, 1998). Os descritores oficiais prescritos nessa lei são baseados em características morfológicas, as quais têm sido utilizadas, porém, algumas limitações têm colocado em dúvida a eficiência desses marcadores.

Com o presente trabalho, objetivou-se avaliar a eficiência dos descritores morfológicos em cultivares comerciais de arroz, visando a identificação de cultivares e a certificação da pureza varietal.

\section{MATERIAL E MÉTODOS}

Foram conduzidos experimentos durante as safras 2000/2001 e 2001/2002. Nesses experimentos foram analisadas as cultivares de arroz de terras altas Carisma, IAC 202, Confiança, Douradão, Guarani, Primavera, Canastra e Caiapó.

O experimento realizado na safra 2000/2001, conduzido em casa-de-vegetação, no Departamento de Agricultura da Universidade Federal de Lavras, teve como objetivo a caracterização das cultivares de arroz. Para tanto, a semeadura foi realizada em vasos plásticos, sendo semeadas seis sementes por vaso, deixando-se duas plantas, após realizado um desbaste, por vaso, o qual constituía uma repetição. Foi utilizado o delineamento inteiramente casualizado, com quatro repetições para cada cultivar.

Os descritores morfológicos avaliados foram os recomendados para o registro e proteção de cultivares, além de outros, considerados aptos, observados nos diferentes estádios de desenvolvimento das plantas.

Para a análise estatística dos dados quantitativos foi utilizado o teste de Scott-Knott 1\%, com o auxílio do “software" Sisvar, Versão 4.0 (FERREIRA, 1999).

O experimento na safra 2001/2002 foi instalado na área experimental da EPAMIG (Empresa de Pesquisa Agropecuária de Minas Gerais), Lavras, sendo utilizados os descritores recomendados para o registro e proteção de cultivares, para fins de certificação da pureza varietal.

Foi utilizado o delineamento de blocos casualizados, com quatro repetições, sendo cada parcela constituída por uma linha de cada cultivar e cada linha possuía 100 plantas com valores entre $0 \%$ e $20 \%$ de contaminação de uma segunda cultivar. O espaçamento entre plantas foi de 0,20 m e entre linhas 0,50 m. Durante a semeadura, a localização das sementes das cultivares contaminantes foi marcada com estacas. Após o desbaste, as estacas foram retiradas e o controle da posição das plantas contaminantes foi feito por meio de um croqui.

As cultivares utilizadas como contaminantes foram IAC 202 em Carisma, Canastra em IAC 202, Canastra em Confiança, Carisma em Primavera, Douradão em Guarani, Primavera em Douradão, Carisma em Canastra e Canastra em Caiapó.

Ao final de cada parcela a ser avaliada, foi instalada uma linha com quinze plantas da cultivar predominante na linha, com o objetivo de facilitar a identificação das contaminantes.

As avaliações foram realizadas por três avaliadores que desconheciam a porcentagem de contaminação, apenas sabendo da porcentagem máxima possível presente em cada linha. As plantas foram avaliadas individualmente e o avaliador apontava aquelas julgadas contaminantes. As plantas foram avaliadas aos 40, 80, 100 e 120 dias após a semeadura. A cada avaliação, foram expostas aos avaliadores as características previstas como descritores. Os avaliadores também consideraram outras características que julgaram importantes para diferenciar as cultivares.

Além das avaliações no campo, as sementes foram avaliadas em laboratório. Para esta avaliação, as sementes foram dispostas lado a lado em folhas de papel, sendo utilizado o mesmo delineamento, número de repetições e percentual de contaminantes utilizados no campo.

Foram calculadas as porcentagens de acerto e erro com base nos resultados obtidos nas avaliações. A porcentagem de acerto foi calculada pelo quociente entre a freqüência observada e a freqüência esperada, multiplicado por cem. No cálculo da porcentagem de erro foram consideradas as plantas contaminantes que não foram identificadas pelos avaliadores e as não contaminantes que foram identificadas como contaminantes. O somatório dessas plantas foi dividido pelo número total de plantas na parcela e multiplicado por cem.

Foi calculado o desvio padrão da média dos resultados nas quatro repetições obtidas pelos três avaliadores, conforme Gomes (1987).

Para verificar a significância dos desvios ocorridos entre os resultados obtidos pelos avaliadores foi utilizado o teste qui-quadrado $\left(\chi^{2}\right)$. Neste teste, os desvios foram transformados em um único valor de $\chi^{2}$, representando a medida padronizada da magnitude dos desvios (RAMALHO et al., 2000). O valor de $\chi^{2}$ foi estimado pela seguinte expressão: 


$$
\chi^{2}=\Sigma(\mathrm{Fo}-\mathrm{Fe})^{2} / \mathrm{Fe}
$$

sendo:

Fo: frequiência observada de contaminantes

Fe: freqüência esperada de contaminantes

Os dados de frequiência esperada e observada foram obtidos da média de quatro repetições para cada avaliador.

\section{RESULTADOS E DISCUSSÃO}

\section{Experimento safra 2000/2001 - caracterização de cultivares}

Os resultados obtidos na caracterização dos genótipos em casa-de-vegetação, baseados nos descritores recomendados para o registro e proteção de cultivares, estão nas Tabelas 1 e 2 .

A seguir serão abordados os descritores que apresentaram polimorfismo entre as cultivares estudadas.

O comprimento do limbo separou as cultivares em dois grupos. Apesar disso, essa característica é pouco estável, pois foi observada acentuada variação entre plantas da mesma cultivar, sendo assim, dificilmente poderá servir para identificar plantas atípicas em uma lavoura. Por outro lado, a pubescência no limbo foi considerada um excelente descritor, pois, aos quinze dias após a semeadura, foi possível diferenciar a cultivar Guarani das demais, por essa ser a única cultivar a apresentar pubescência no limbo.

$\mathrm{O}$ ângulo da folha bandeira foi classificado como ereto em todas as cultivares estudadas, com exceção da IAC 202, que apresentou ângulo intermediário. Segundo Fonseca et al. (2002), os ângulos da folha bandeira e dos afilhos são características inerentes à cultivar e raramente são modificados pelo ambiente.

O comprimento do colmo, característica que separou as cultivares em dois grupos, está relacionada com o porte da planta. Essa é outra característica muito influenciada pelo ambiente, principalmente pelas altas dosagens de nitrogênio (FONSECA et al., 2002).

A característica dias para emissão da panícula, variou de cultivar para cultivar, sendo esta característica muito importante na definição do ciclo. As cultivares precoces, médias e tardias diferenciam-se pela duração da fase germinativa até a floração, ou seja, durante o estádio vegetativo. Essa característica é influenciada pela temperatura e fotoperíodo (SOARES, 1997). Acredita-se que, durante a condução do experimento, o ciclo das cultivares foi acelerado, devido à alta temperatura na casa-de-vegetação.

O comprimento da panícula separou as cultivares em dois grupos. Essa característica pode ser influenciada pelo ambiente e dificilmente, em um campo de produção, seria decisiva para diferenciação de cultivares. Isso é confirmado pela conclusão similar encontrada por Oliveira et al. (1993), que trabalharam com cultivares de arroz brasileiras e japonesas.

Pelo tipo de panícula foi possível separar as cultivares em três grupos, 'Caiapó', 'Canastra', 'Confiança', 'Guarani' e 'Carisma' com panícula intermediária; 'Douradão' apresentou panícula compacta e 'Primavera', aberta. Embora essa característica tenha permitido a discriminação de algumas cultivares, a ocorrência de estiagens na época da emissão e na floração podem influenciar o comportamento dessa característica (FONSECA et al., 2002).

A excerção das panículas foi classificada como justa na cultivar IAC 202 e média em todas as outras. Esses resultados discordam dos publicados por Bastos (2000) para a cultivar IAC 202, que detectou excerção intermediária e dos publicados por EPAMIG (199_) que afirmam que a cultivar Carisma possui excerção completa. Essa discordância pode ser explicada pela influência do ambiente sobre essa característica, principalmente nas fases de emissão da panícula e floração (FONSECA et al., 2002).

O degrane foi classificado como fácil na cultivar Douradão e intermediário nas demais. Esses resultados discordam dos encontrados por Epamig (1997) para a cultivar Canastra, que foi classificada como apresentando degrane fácil.

A presença das aristas foi observada nas cultivares Canastra, Guarani e IAC 202, sendo na Canastra classificada quanto ao comprimento como curta e na cv. IAC 202 como média. O comprimento das aristas nessas cultivares não foi estável apresentando sementes aristadas e não aristadas. Soares (1997) afirma que, freqüentemente, é observada variação acentuada no desenvolvimento da arista, não só dentro da mesma planta, mas também dentro da panícula..

A cor do estigma nas cultivares Douradão e Carisma foi amarela, enquanto que em todas as outras cultivares foi branca. Destaca-se nessa característica a dificuldade em diferenciar estigmas brancos de verde-claro e amarelo, devido à proximidade das cores, além da influência da luminosidade na definição da cor no momento da avaliação.

A pubescência das glumelas estava presente apenas na cultivar Guarani. Menezes \& Romero (1996), trabalhando com 22 cultivares de arroz irrigado, as distingüiram pela pilosidade nas glumelas em dois grupos. Esses autores consideraram que, pela falta de estabilidade, é comum aparecerem misturas físicas entre os grupos, fato confirmado pela descrição da cultivar Douradão quando é prevista a presença de até $0,5 \%$ de grãos pilosos (EPAMIG, 198_). 
TABELA 1 - Caracterização morfológica de oito cultivares de arroz de sequeiro.

\begin{tabular}{|c|c|c|c|c|c|c|c|c|}
\hline & Canastra & Primavera & Carisma & Guarani & Caiapó & Douradão & Confiança & IAC 202 \\
\hline Cor folha & Verde & Verde & Verde & Verde & Verde & Verde & Verde & Verde \\
\hline $\begin{array}{l}\text { Pubescência do } \\
\text { limbo }\end{array}$ & Ausente & Ausente & Ausente & Forte & Ausente & Ausente & Ausente & Ausente \\
\hline Cor aurícula & Verde-claro & Verde-claro & Verde-claro & Verde-claro & Verde-claro & Verde-claro & Verde-claro & Verde-claro \\
\hline Cor lígula & $\begin{array}{l}\text { Incolor a } \\
\text { verde }\end{array}$ & $\begin{array}{l}\text { Incolor a } \\
\text { verde }\end{array}$ & $\begin{array}{l}\text { Incolor a } \\
\text { verde }\end{array}$ & $\begin{array}{l}\text { Incolor a } \\
\text { verde }\end{array}$ & $\begin{array}{l}\text { Incolor a } \\
\text { verde }\end{array}$ & $\begin{array}{l}\text { Incolor a } \\
\text { verde }\end{array}$ & $\begin{array}{l}\text { Incolor a } \\
\text { verde }\end{array}$ & $\begin{array}{l}\text { Incolor a } \\
\text { verde }\end{array}$ \\
\hline $\begin{array}{l}\text { Ângulo da } \\
\text { folha bandeira }\end{array}$ & Ereto & Ereto & Ereto & Ereto & Ereto & Ereto & Ereto & Intermediário \\
\hline $\begin{array}{l}\text { Ângulo dos } \\
\text { afilhos }\end{array}$ & Ereto & Ereto & Ereto & Ereto & Ereto & Ereto & Ereto & Ereto \\
\hline $\begin{array}{l}\text { Cor do } \\
\text { internódio }\end{array}$ & Verde-Claro & Verde-claro & Verde-claro & Verde-claro & Verde-claro & Verde-claro & Verde-claro & Verde-claro \\
\hline $\begin{array}{l}\text { Antocianina } \\
\text { nos nós }\end{array}$ & Ausente & Ausente & Ausente & Ausente & Ausente & Ausente & Ausente & Ausente \\
\hline $\begin{array}{l}\text { Dias emissão } \\
\text { da panícula }\end{array}$ & 55 & 40 & 50 & 43 & 54 & 40 & 43 & 38 \\
\hline $\begin{array}{l}\text { Tipo de } \\
\text { panícula }\end{array}$ & Intermediária & Aberta & Intermediária & Intermediária & Intermediária & Compacta & Intermediária & Intermediária \\
\hline $\begin{array}{l}\text { Exserção da } \\
\text { panículas }\end{array}$ & Média & Média & Média & Média & Média & Média & Média & Justa \\
\hline Degrane & Intermediário & Intermediário & Intermediário & Intermediário & Intermediário & Fácil & Intermediário & Intermediário \\
\hline $\begin{array}{l}\text { Presença das } \\
\text { aristas }\end{array}$ & Microaristas & Ausente & Ausente & Microaristas & Ausente & Ausente & Ausente & $1 / 2$ superior \\
\hline $\begin{array}{l}\text { Comprimento } \\
\text { das aristas }\end{array}$ & Curta & Ausente & Ausente & Curta & Ausente & Ausente & Ausente & Média \\
\hline $\begin{array}{l}\text { Cor estigma } \\
\text { (espiguetas) }\end{array}$ & Branca & Branca & Amarela & Branca & Branca & Amarela & Branca & Branca \\
\hline $\begin{array}{l}\text { Pubescencia } \\
\text { glumelas }\end{array}$ & Ausente & Ausente & Ausente & Forte & Ausente & Ausente & Ausente & Ausente \\
\hline $\begin{array}{l}\text { Cor apículo na } \\
\text { floração }\end{array}$ & Verde & Marrom & Púrpura & Verde & Púrpura & Branca & Verde & Verde \\
\hline $\begin{array}{l}\text { Cor apículo } \\
\text { maturação }\end{array}$ & Verde & Marrom & Marrom & Marrom & Marrom & Amarelo & Marrom & Marrom \\
\hline $\begin{array}{l}\text { Cor glumas } \\
\text { estéreis }\end{array}$ & Palha & Palha & Palha & Palha & Palha & Palha & Palha & Palha \\
\hline $\begin{array}{l}\text { Cor do grão } \\
\text { descascado }\end{array}$ & Branca & Branca & Branca & Branca & Branca & Branca & Branca & Branca \\
\hline $\begin{array}{l}\text { Forma do grão } \\
\text { descascado }\end{array}$ & Alongado & Alongado & Alongado & Alongado & Alongado & Alongado & Alongado & Alongado \\
\hline Ciclo cultural & Médio & Curto & Curto & Curto & Médio & Curto & Médio & Curto \\
\hline
\end{tabular}

A cor do apículo é uma característica muito útil na diferenciação de cultivares, pois, com base nesse descritor, os genótipos estudados puderam ser divididos em cinco grupos de acordo com a combinação de cores do apículo na floração e maturação.

As cultivares Caiapó e Carisma apresentaram antocianina na base dos colmos, característica essa verificada durante o perfilhamento. Porém, essa pigmentação não foi observada quando da instalação do experimento em campo, provavelmente devido à influência do ambiente. A herança da pigmentação de antocianina é bastante complexa devido à existência de locos duplicados, série alélica múltipla para um mesmo loco, fatores inibidores, diferenças sutis na tonalidade e intensidade de cor entre genótipos, variação nos estádios de crescimento e o efeito acentuado de fatores ambientais, como a luz, sobre o desenvolvimento da cor. 
TABELA 2 - Características morfológicas quantitativas de oito cultivares de arroz de sequeiro.

\begin{tabular}{lccccc}
\hline \multicolumn{1}{c}{ Cultivar } & $\begin{array}{c}\text { Comprimento } \\
\text { do limbo (cm) }\end{array}$ & $\begin{array}{c}\text { Largura do } \\
\text { limbo }(\mathbf{c m})\end{array}$ & $\begin{array}{c}\text { Comprimento do } \\
\text { colmo (cm) }\end{array}$ & $\begin{array}{c}\text { Comprimento da } \\
\text { panícula (cm) }\end{array}$ & $\begin{array}{c}\text { Espessura do } \\
\text { colmo (cm) }\end{array}$ \\
\hline Guarani & $42,0 \mathrm{~B}$ & $1,28 \mathrm{C}$ & $61,0 \mathrm{~B}$ & $18,88 \mathrm{~A}$ & $0,63 \mathrm{C}$ \\
Primavera & $39,0 \mathrm{~B}$ & $1,14 \mathrm{~B}$ & $68,3 \mathrm{~B}$ & $22,13 \mathrm{~B}$ & $0,48 \mathrm{~B}$ \\
Douradão & $48,0 \mathrm{~B}$ & $1,26 \mathrm{C}$ & $62,0 \mathrm{~B}$ & $20,60 \mathrm{~B}$ & $0,45 \mathrm{~B}$ \\
Canastra & $24,0 \mathrm{~A}$ & $1,13 \mathrm{~B}$ & $52,0 \mathrm{~A}$ & $16,93 \mathrm{~A}$ & $0,38 \mathrm{~A}$ \\
Caiapó & $39,0 \mathrm{~B}$ & $1,35 \mathrm{C}$ & $61,5 \mathrm{~B}$ & $18,00 \mathrm{~A}$ & $0,45 \mathrm{~B}$ \\
IAC 202 & $32,0 \mathrm{~A}$ & $1,28 \mathrm{C}$ & $46,0 \mathrm{~A}$ & $16,37 \mathrm{~A}$ & $0,38 \mathrm{~A}$ \\
Carisma & $25,0 \mathrm{~A}$ & $0,93 \mathrm{~A}$ & $54,0 \mathrm{~A}$ & $16,28 \mathrm{~A}$ & $0,40 \mathrm{~A}$ \\
Confiança & $32,0 \mathrm{~A}$ & $1,30 \mathrm{C}$ & $48,0 \mathrm{~A}$ & $17,88 \mathrm{~A}$ & $0,40 \mathrm{~A}$ \\
\hline F (Tratamento) & 7,27 & 9,63 & 7,75 & 12,61 & 20,7 \\
CV (\%) & 18,06 & 7,35 & 9,86 & 6,36 & 8,17 \\
\hline
\end{tabular}

Letras não comuns na coluna indicam diferenças significativas pelo teste de Scott-Knott ao nível de $1 \%$.

O ciclo cultural permitiu diferenciar as cultivares em dois grupos distintos, com ciclo médio e curto. Porém, variações no ciclo podem ocorrer devido à época de semeadura e condições climáticas (FONSECA et al., 2000).

Quanto à análise morfológica de sementes (Tabela 3), foram observadas diferenças significativas, no mínimo, em três cultivares por característica. $\mathrm{O}$ comprimento dos grãos com glumelas diferenciou a cultivar Confiança das demais. Já o comprimento sem glumelas permitiu a separação das cultivares em três grupos. A largura das sementes permitiu o agrupamento das cultivares em quatro grupos, sendo considerada uma característica de fácil determinação. A característica espessura dos grãos permitiu a separação das cultivares em dois grupos. Essa característica, devido às pequenas diferenças de medida é de difícil utilização prática para a determinação da diferenciação de cultivares e para certificação da pureza varietal de um lote de sementes. Conclusão similar foi encontrada por Menezes \& Romero (1996) quando trabalharam com essa característica na separação varietal de arroz, afirmando que a espessura não mostrou diferenças significativas entre as cultivares que a credenciassem como característica útil na distinção varietal.

A característica peso de grãos foi a que melhor separou os materiais, sendo formados cinco grupos. Porém segundo Maeda et al. (1995), alguns cuidados devem ser tomados pois, além da determinação genética, essa característica pode ser influenciada pelas condições climáticas e/ou manejo, variando consideravelmente entre lotes.

Quanto à forma dos grãos, as cultivares Canastra, Carisma, Guarani, Douradão, Confiança e IAC 202 foram classificadas como forma alongada, Primavera como muito alongada e Caiapó meio-alongada. Quanto à cor das glumelas, as cultivares Douradão e Confiança apresentaram cor dourada, as demais cultivares apresentaram cor palha.

A caracterização morfológica realizada até o estádio de antese foi pouco eficiente, sendo o número de marcadores polimórficos encontrado considerado baixo. Os marcadores mais valorosos observados nessa pesquisa ocorrem após esse período.

Destacamos, a partir dos resultados obtidos, que as características de pubescência do limbo, dias para emissão da panícula, tipo de panícula, excerção das panículas, presença de aristas, pubescência nas glumelas, cor do apículo e características das sementes são as que fornecem as melhores características diferenciais entre as cultivares. Porém, é importante salientar que a diferenciação ocorre com a análise, não de apenas uma, mas de um conjunto de características. Além disso, a comparação deve ocorrer entre cultivares desenvolvidas sob o mesmo ambiente. 
TABELA 3 - Características morfológicas das sementes de oito cultivares de arroz de sequeiro.

\begin{tabular}{|c|c|c|c|c|c|c|c|c|}
\hline \multirow[b]{2}{*}{ Cultivar } & \multicolumn{5}{|c|}{ Com glumelas } & \multicolumn{3}{|c|}{ Sem glumelas } \\
\hline & $\begin{array}{c}\text { Comprimento } \\
\text { (cm) }\end{array}$ & $\begin{array}{c}\text { Largura } \\
(\mathrm{cm})\end{array}$ & Espessura & Comp/larg & $\begin{array}{c}\text { Peso } \\
100\end{array}$ & Comprimento & Largura & Comp/larg \\
\hline Guarani & $0,98 \mathrm{~A}$ & $0,29 \mathrm{D}$ & $0,22 \mathrm{~A}$ & $3,41 \quad \mathrm{~B}$ & $3,39 \mathrm{D}$ & $0,76 \mathrm{C}$ & $0,27 \mathrm{D}$ & $2,80 \mathrm{~A}$ \\
\hline Primavera & $0,97 \mathrm{~A}$ & $0,23 \mathrm{~A}$ & $0,20 \mathrm{~B}$ & $4,15 \mathrm{D}$ & $2,72 \mathrm{C}$ & $0,75 \mathrm{C}$ & $0,21 \mathrm{~A}$ & $3,57 \mathrm{D}$ \\
\hline Douradão & $0,97 \mathrm{~A}$ & $0,30 \mathrm{D}$ & $0,22 \mathrm{~A}$ & $3,24 \mathrm{~A}$ & $3,52 \mathrm{E}$ & $0,75 \mathrm{C}$ & $0,26 \mathrm{D}$ & $2,83 \mathrm{~A}$ \\
\hline Canastra & $0,94 \mathrm{~B}$ & $0,27 \mathrm{C}$ & $0,21 \mathrm{~B}$ & $3,50 \mathrm{~B}$ & $2,73 \mathrm{C}$ & $0,72 \mathrm{~B}$ & $0,23 \mathrm{~B}$ & $3,08 \mathrm{~B}$ \\
\hline Caiapó & $0,92 \mathrm{~B}$ & $0,28 \mathrm{D}$ & $0,23 \mathrm{~A}$ & $3,23 \mathrm{~A}$ & $2,78 \mathrm{C}$ & & $0,25 \mathrm{C}$ & $2,72 \mathrm{~A}$ \\
\hline IAC 202 & $0,92 \mathrm{~B}$ & $0,23 \mathrm{~A}$ & $0,20 \mathrm{~B}$ & $3,90 \mathrm{C}$ & $2,36 \mathrm{~B}$ & $0,70 \mathrm{~B}$ & $0,22 \mathrm{~A}$ & $3,20 \mathrm{C}$ \\
\hline Carisma & $0,92 \mathrm{~B}$ & $0,22 \mathrm{~A}$ & $0,20 \mathrm{~B}$ & $4,07 \mathrm{D}$ & $2,44 \mathrm{~B}$ & $0,72 \mathrm{~B}$ & $0,22 \mathrm{~A}$ & $3,29 \mathrm{C}$ \\
\hline Confiança & $0,81 \mathrm{C}$ & $0,25 \mathrm{~B}$ & $0,21 \mathrm{~B}$ & $3,16 \mathrm{~A}$ & $2,15 \mathrm{~A}$ & $0,63 \mathrm{~A}$ & $0,22 \mathrm{~A}$ & $2,88 \mathrm{~A}$ \\
\hline F (Tratamento) & 44,55 & 75,04 & 8,37 & 68,80 & 488,25 & 60,13 & 51,97 & 53,69 \\
\hline $\mathrm{CV}(\%)$ & 1,76 & 2,45 & 2,62 & 2,69 & 1,57 & 1,60 & 2,84 & 2,62 \\
\hline
\end{tabular}

Letras não comuns na coluna indicam diferenças significativas pelo teste de Scott-Knott ao nível de $1 \%$.

\section{Experimento safra 2001/2002}

Os resultados médios de acertos e erros obtidos durante a análise da pureza varietal no experimento na safra 2001/2002 estão apresentados na Tabela 4.

$\mathrm{Na}$ avaliação realizada aos 40 dias após a semeadura, destacou-se, a cultivar Guarani, com a maior porcentagem de acertos e a menor porcentagem de erros. Isso ocorreu devido à presença de acentuada pubescência no limbo desde os estádios iniciais de desenvolvimento das plantas da cultivar Guarani. Essa característica a distingüiu com facilidade da contaminante.

Aos 80 dias após a semeadura, a porcentagem de acerto das plantas contaminantes na cultivar Guarani foi a menor, $6,6 \%$ e a maior porcentagem de erro, $17,3 \%$. Esse resultado não foi esperado, pois a pilosidade do limbo das folhas da cultivar Guarani é uma característica inerente à cultivar.

Na avaliação aos 100 dias após a semeadura, com exceção das cultivares Caiapó e Carisma, todas as contaminantes das outras cultivares foram diferenciadas com maior porcentagem de acerto do que na avaliação anterior. Nessa fase, a maioria das cultivares encontravase na fase de floração, facilitando a diferenciação, pois o número de caracteres a serem observados era maior que em fases anteriores.

Aos 120 dias após a semeadura foram observadas, para a maioria das cultivares, as maiores porcentagens de acerto desde a fase de germinação. A menor porcentagem de acerto foi verificada na cultivar Primavera, ocorrendo diminuição na porcentagem de acerto quando comparada à avaliação aos 80 dias. Acredita-se que isso possa ser explicado pelo fato da cultivar Primavera apresentar ciclo curto, assim como a 'Carisma', sua contaminante, dificultando a diferenciação.

Os maiores níveis de acertos de contaminantes foram observados com os descritores analisados em sementes, com percentuais superiores aos detectados durante o ciclo vegetativo. Exceção foi observada para a cultivar Carisma na qual, aos 120 dias foram observados $80,2 \%$ de acerto e, por ocasião da análise de sementes, foram observados $77,7 \%$ de acerto.

Quando analisados os dados de acerto e erro comparando todas as fases de avaliação, pode-se afirmar que os contaminantes foram melhor identificados quando analisados em sementes maduras. Nas avaliações em campo, a cultivar Guarani foi a que obteve a melhor diferenciação da sua contaminante, cv. Douradão, nas primeiras fases de desenvolvimento vegetativo. A cultivar Primavera, em todas as fases de avaliação, pareceu ser a de mais difícil diferenciação em relação a sua contaminante, cultivar Carisma, apresentando as menores porcentagens de acerto.

Com base nos resultados da Tabela 4, pode-se afirmar que para a identificação de contaminantes, com exceção da cultivar Guarani, quanto mais avançado estiver o estádio de desenvolvimento das plantas, maiores são as possibilidades de identificação de contaminantes. Até o início da antese, as cultivares são muito similares morfologicamente, sendo necessário, para a discriminação, o auxílio de testes de natureza bioquímica ou molecular. Os estádios tardios, quando são observadas as características diferenciais, são uma das principais desvantagens dessa classe de

Ciênc. agrotec., Lavras, v. 31, n. 3, p. 619-627, maio/jun., 2007 
TABELA 4 - Resultados, acerto e erro, de plantas contaminantes, determinado por três avaliadores, com base em características morfológicas em diferentes épocas de avaliação.

\section{Época de avaliação}

\begin{tabular}{|c|c|c|c|c|c|c|}
\hline \multirow[t]{2}{*}{ Cultivar } & & \multicolumn{5}{|c|}{ Dias após semeadura } \\
\hline & & Sementes & 40 & 80 & 100 & 120 \\
\hline \multirow[t]{2}{*}{ Canastra } & $\%$ acerto & $94,9 \pm 1,5$ & $3,6 \pm 3,6$ & $7,7 \pm 2,6$ & $64,1 \pm 19,9$ & $86,5 \pm 7,9$ \\
\hline & $\%$ erro & $1,0 \pm 0,3$ & $12,8 \pm 1,7$ & $16,3 \pm 1,7$ & $10,5 \pm 4,9$ & $3,9 \pm 0,9$ \\
\hline \multirow[t]{2}{*}{ Primavera } & $\%$ acerto & $63,7 \pm 39,2$ & $5,1 \pm 1,9$ & $18,0 \pm 15,8$ & $25,7 \pm 19,5$ & $12,7 \pm 10,9$ \\
\hline & $\%$ erro & $6,6 \pm 5,2$ & $15,0 \pm 4,3$ & $16,1 \pm 4,6$ & $17,2 \pm 4,6$ & $18,9 \pm 7,3$ \\
\hline \multirow[t]{2}{*}{ Carisma } & $\%$ acerto & $77,7 \pm 9,1 *$ & $8,0 \pm 3,7$ & $60,7 \pm 13,9$ & $48,4 \pm 7,4$ & $80,2 \pm 12,8$ \\
\hline & $\%$ erro & $2,0 \pm 0,4$ & $17,3 \pm 3,1$ & $8,2 \pm 2,1$ & $11,6 \pm 1,9$ & $6,1 \pm 2,0$ \\
\hline \multirow[t]{2}{*}{ Guarani } & $\%$ acerto & $86,9 \pm 16,8$ & $86,0 \pm 12,8$ & $6,6 \pm 7,6$ & $53,8 \pm 24,7$ & $78,8 \pm 3,0$ \\
\hline & $\%$ erro & $1,9 \pm 2,5$ & $3,8 \pm 1,6$ & $17,3 \pm 2,4$ & $9,4 \pm 6,9$ & $7,0 \pm 5,2$ \\
\hline \multirow[t]{2}{*}{ Caiapó } & $\%$ acerto & $94,3 \pm 5,3$ & $8,8 \pm 3,7$ & $54,2 \pm 8,1$ & $23,1 \pm 14,9$ & $75,3 \pm 14,3$ \\
\hline & $\%$ erro & $1,5 \pm 0,9$ & $13,6 \pm 2,4$ & $8,9 \pm 2,6$ & $15,9 \pm 1,5$ & $3,3 \pm 2,3$ \\
\hline \multirow[t]{2}{*}{ Douradão } & $\%$ acerto & $88,2 \pm 4,6$ & $14,4 \pm 8,6$ & $39,6 \pm 12,8$ & $47,4 \pm 25,4$ & $45,2 \pm 18,2$ \\
\hline & $\%$ erro & $1,6 \pm 0,4$ & $9,6 \pm 1,7$ & $8,9 \pm 3,2$ & $7,7 \pm 6,4$ & $5,8 \pm 1,0$ \\
\hline \multirow[t]{2}{*}{ Confiança } & $\%$ acerto & $81,3 \pm 1,9$ & $9,8 \pm 4,0$ & $21,8 \pm 3,5$ & $43,4 \pm 6,6$ & $66,0 \pm 17,3$ \\
\hline & $\%$ erro & $3,3 \pm 1,2$ & $17,8 \pm 1,3$ & $14,7 \pm 3,0$ & $14,9 \pm 3,1$ & $5,3 \pm 2,9$ \\
\hline \multirow[t]{2}{*}{ IAC 202} & $\%$ acerto & $90,5 \pm 3,1$ & $13,6 \pm 6,5$ & $26,3 \pm 10,7$ & $26,3 \pm 9,4$ & $74,8 \pm 12,1$ \\
\hline & $\%$ erro & $5,1 \pm 2,6$ & $11,8 \pm 1,9$ & $12,8 \pm 0,1$ & $16,0 \pm 0,9$ & $3,4 \pm 0,9$ \\
\hline
\end{tabular}

* Desvio padrão da média.

marcadores, pois, para a obtenção dos resultados, demandam muito tempo comparado a outros marcadores. A partir dos resultados do teste qui-quadrado (Tabela 5) aplicado aos dados encontrados pelos avaliadores observou-se que na análise de sementes maduras, assim como nos demais estádios de desenvolvimento, os resultados do qui-quadrado foram significativos para a cultivar Primavera.

$\mathrm{Na}$ avaliação realizada aos 40 dias, à exceção da cultivar Guarani, e aos 80 dias à exceção da Cultivar Carisma, para todas as outras, os resultados do qui-quadrado foram significativos. Aos 100 dias, apenas para a cultivar Canastra os resultados não mostraram significância. Aos 120 dias, 'Douradão', 'Confiança' e 'Primavera' apresentaram significância; para todas as outras, os desvios foram aceitos como sendo ao acaso.

É importante esclarecer que, quando ocorreu a significância dos desvios na avaliação, significou que os erros não foram ao acaso e, sim, a outras causas, como, por exemplo, a ausência de características morfológicas diferenciais. O grande número de desvios significativos observados indica que, nesses períodos, os marcadores morfológicos não foram adequados para a diferenciação das cultivares, dentro dos níveis de significância propostos.

É importante ressaltar que a avaliação de alguns descritores é dificultada pela ausência de um padrão de classificação dentro de cada descritor. 
TABELA 5 - Resultados do teste qui-quadrado $\left(\chi^{2}\right)$ aplicados aos dados de identificação de contaminantes, em várias épocas de avaliação, obtidos por três avaliadores.

\section{Época de avaliação}

\section{Cultivar}

Dias após semeadura

\begin{tabular}{|c|c|c|c|c|c|c|}
\hline & Avaliador & Sementes & 40 & 80 & 100 & 120 \\
\hline \multirow{4}{*}{ Canastra } & 1 & 0,03 & 7,5 & 6,59 & 3,33 & 0,49 \\
\hline & 2 & 0,06 & 6,59 & 6,15 & 0,23 & 0,03 \\
\hline & 3 & 0,07 & 7,02 & 6,12 & 0,74 & 0,35 \\
\hline & $\chi^{2}$ & $0,16 \mathrm{NS}$ & $21,11 * *$ & $18,86^{* *}$ & $4,30 \mathrm{NS}$ & $0,87 \mathrm{NS}$ \\
\hline \multirow{4}{*}{ Primavera } & 1 & 0,21 & 7,07 & 5,38 & 7,08 & 8,00 \\
\hline & 2 & 0,33 & 7,56 & 7,52 & 2,08 & 2,23 \\
\hline & 3 & 7,17 & 7,53 & 2,56 & 5,06 & 6,16 \\
\hline & $\chi^{2}$ & $7,71^{*}$ & $22,16^{* *}$ & $15,46 * *$ & $14,22 * *$ & $16,39 * *$ \\
\hline \multirow{4}{*}{ Carisma } & 1 & 0,36 & 9,28 & 3,85 & 4,01 & 0,02 \\
\hline & 2 & 0,78 & 8,47 & 1,10 & 2,22 & 0,95 \\
\hline & 3 & 0,24 & 8,34 & 0,96 & 2,20 & 0,83 \\
\hline & $\chi^{2}$ & $1,38 \mathrm{NS}$ & $26,09 * *$ & $5,91 \mathrm{NS}$ & $8,43^{*}$ & $1,80 \mathrm{NS}$ \\
\hline \multirow{4}{*}{ Guarani } & 1 & 0,00 & 0,03 & 9,75 & 6,36 & 0,58 \\
\hline & 2 & 0,03 & 0,12 & 0,75 & 1,08 & 0,43 \\
\hline & 3 & 1,82 & 1,22 & 7,52 & 0,99 & 1,17 \\
\hline & $\chi^{2}$ & $1,85 \mathrm{NS}$ & $1,37 \mathrm{NS}$ & $18,02 * *$ & $8,43 *$ & $2,18 \mathrm{NS}$ \\
\hline \multirow{4}{*}{ Caiapó } & 1 & 0,02 & 6,97 & 3,75 & 5,84 & 0,20 \\
\hline & 2 & 0,02 & 6,48 & 1,73 & 3,00 & 0,60 \\
\hline & 3 & 0,52 & 8,29 & 1,51 & 7,83 & 1,86 \\
\hline & $\chi^{2}$ & $0,56 \mathrm{NS}$ & $21,74 * *$ & $6,99 *$ & $16,67 * *$ & $2,66 \mathrm{NS}$ \\
\hline \multirow{4}{*}{ Douradão } & 1 & 0,11 & 4,39 & 4,30 & 5,77 & 3,40 \\
\hline & 2 & 0,30 & 2,51 & 6,15 & 0,94 & 1,75 \\
\hline & 3 & 0,50 & 4,39 & 2,80 & 0,61 & 1,45 \\
\hline & $\chi^{2}$ & $0,91 \mathrm{NS}$ & $11,29 * *$ & $13,25 * *$ & $7,32 *$ & $6,60 *$ \\
\hline \multirow{4}{*}{ Confiança } & 1 & 0,47 & 9,94 & 8,09 & 3,99 & 1,39 \\
\hline & 2 & 0,74 & 8,54 & 5,50 & 2,39 & 1,80 \\
\hline & 3 & 0,33 & 9,82 & 8,28 & 4,01 & 2,80 \\
\hline & $\chi^{2}$ & $1,54 \mathrm{NS}$ & $28,3 * *$ & $21,87 * *$ & $10,39 * *$ & $5,99 *$ \\
\hline \multirow{4}{*}{ IAC 202} & 1 & 0,05 & 5,62 & 4,01 & 3,34 & 0,93 \\
\hline & 2 & 0,27 & 3,70 & 3,97 & 5,03 & 0,36 \\
\hline & 3 & 0,15 & 5,21 & 4,32 & 4,73 & 2,31 \\
\hline & $\chi^{2}$ & $0,47 \mathrm{NS}$ & $14,53 * *$ & $12,30 * *$ & $13,10 * *$ & $3,60 \mathrm{NS}$ \\
\hline
\end{tabular}

** - Significativo a $1 \%$ de probabilidade; * - Significativo a $5 \%$ de probabilidade .

NS - Não-significativo.

\section{CONCLUSÕES}

Os descritores morfológicos não são suficientes para a caracterização e diferenciação de cultivares de arroz de sequeiro.
As características morfológicas observadas em sementes e plantas após a antese são as mais adequadas para a caracterização e diferenciação de cultivares. 


\section{AGRADECIMENTOS}

Ao CNPq, pela bolsa concedida ao primeiro autor e a EPAMIG - Lavras, pela infra-estrutura cedida.

\section{REFERÊNCIAS BIBLIOGRÁFICAS}

BASTOS, C. R. IAC 202: arroz de alta produtividade e qualidade para cultura de sequeiro. O Agronômico, Campinas, v. 52, n. 1, 2000.

EMPRESA DE PESQUISA AGROPECUÁRIA DE MINAS GERAIS. Douradão: nova cultivar de arroz de sequeiro para Minas Gerais. Belo Horizonte, [198-]. Folder.

EMPRESA DE PESQUISA AGROPECUÁRIA DE MINAS GERAIS. Canastra e confiaça arroz agulhinha para plantio em condições de sequeiro e sob pivô central. Belo Horizonte: EPAMIG-UFLA-EMBRAPA/CNPAF-UFV, 1997. Folder.

EMPRESA DE PESQUISA AGROPECUÁRIA DE MINAS GERAIS. Carisma, arroz agulhinha. Belo Horizonte, [199]. Folder.

FERREIRA, D. F. Sisvar. Versão 4.0. Lavras: DEX-UFLA, 1999.

FONSECA, J. R.; CUTRIM, V. A.; RANGEL, P. H. N. Descritores morfo agronômicos e fenológicos de cultivares comerciais de arroz de várzeas. Brasília, DF: Embrapa, 2002. 22 p. (Documentos, 141).

GOFF, S. A.; RICKE, D.; LAU, T. H.; PRETING, G.; WANG, R. L.; DUNN, M. A draft sequence of the rice genome (Oryza sativa L. ssp. japonica). Science, Washington, v. 296, n. 5565, p. 92-100, Apr. 2002.

GOMES, F. P. Curso de estatística experimental. 12. ed. Piracicaba: ESALQ/USP, 1987. 466 p.

GUIDOLIN, A. F. Caracterização de genótipos de arroz irrigado por técnicas eletroforéticas. 1993. $92 \mathrm{f}$.
Dissertação (Mestrado) - Universidade Federal de Pelotas, Pelotas, 1993.

MAEDA, J. A.; ALMEIDA, L. D. A.; JADEROSA, M.; CAMARGO, C. E. O. Discriminação de cultivares de arroz pelas características físicas, fisiológicas ou químicas das sementes e plântulas. Bragantia, Campinas, v. 54, n. 1, p. 17-32, 1995 .

MENEZES, N. L.; ROMERO, C. M. Determinação varietal em arroz. Pesquisa Agropecuária Brasileira, Brasília, v. 31, n. 2, p. 139-146, fev. 1996.

MILACH, S. C. K. Uso de Marcadores moleculares na caracterização de cultivares. In: BORÉM, A. et al. (Eds.). Biossegurança, proteção de cultivares, acesso aos recursos genéticos e propriedade industrial na agropecuária. Viçosa: UFV, 1998. 182 p.

OLIVEIRA, A. C.; DERBYSHIRE, E.; CARVALHO, M. T. V.; ANDO, A. Perfis protéicos de variedades parentais e híbridos de arroz e sua correlação com heterose. Pesquisa Agropecuária Brasileira, Brasília, v. 28, n. 3, p. 313-322, mar. 1993.

PESKE, S. T.; BARROS, A. C. S. A. Produção de sementes. In: PESKE, S. T.; NEDEL, J. L.; BARROS, A. C. S. A. (Eds.). Produção de arroz. Pelotas: UFPEL, 1996. p. 357-422.

RAMALHO, M. A. P.; SANTOS, J. B.; PINTO, C. A. B. P. Genética na agropecuária. Lavras: UFLA, 2000. 472 p.

RIGATTO, P.; KOHLZ, V. K. Economia da produção. In: PESKE, S. T.; NEDEL, J. L.; BARROS, A. C. S. A. (Eds.). Produção de arroz. Pelotas: UFPEL, 1998. p. 555-641.

SOARES, A. A. Genética do arroz. Lavras: UFLA, 1997. 73 p. Apostila. 